Otavio T. Ranzani

\section{Blindness: perceptions under mechanical ventilation}

Received: 4 February 2013

Accepted: 28 February 2013

Published online: 28 March 2013

(C) Springer-Verlag Berlin Heidelberg and ESICM 2013

O. T. Ranzani ( $\bullet)$

Medical Intensive Care Unit, Emergency Medicine Discipline, Hospital das Clínicas, Universidade de São Paulo, Rua Enéas Carvalho de Aguiar, 255, sala 6040, $6^{\circ}$ andar, Cerqueira Cesar, São Paulo 05403-000, Brazil

e-mail: otavioranzani@yahoo.com.br

Tel.: +55-11-26616457

Fax: +55-11-26616336

I wrote these words and constructed these images after conversations with a patient who I attended during my first year of critical care fellowship. He was 71 years old and had been mechanically ventilated two times in his life because of chronic obstructive pulmonary disease exacerbations. After ICU discharge, I followed him until hospital discharge.

When one reaches the ridge

of the stone castle,

the inconsistency of the sea dawns on.

as a baby cry going

to the undesired cradle;

as the birds coming

from a sunny vacation.
When the moon's essence

breaks in through the lonesome thought, the glasses fog up with a cloud of breath! like the window wiping feelings out of smiles,

in the rain.

$$
\text { like butterflies floating }
$$

When one comes upon the edge of the abyss, and life spreads out your arms and you cannot perceive little ants eating up your memories,

the

wind can stroke the inner door,

and then your eyes

must realize:

Life is something

wild

Touching your ears

While your mind

tries

to

puzzle out

the honest truth.

Otavio T. Ranzani 